\title{
Agua e industria en Puebla. El establecimiento de la fábrica textil La Covadonga, 1889-1897
}

\author{
Sergio Francisco Rosas Salas* \\ EL COLEGIO DE MICHOACÁN
}

Durante el siglo XIX se establecieron en la ribera del río Atoyac, en los estados de Puebla y Tlaxcala, 13 fábricas textiles, formando un corredor industrial que aprovechaba la energía hidráulica de esta corriente. El presente artículo analiza el proceso seguido por José Díaz Rubín ante el gobierno federal y los usuarios locales para el establecimiento de la última de ellas: La Covadonga, fundada en 1897. A partir de este caso, el trabajo muestra cómo en el corredor industrial del Atoyac la aplicación de la ley del 5 de junio de 1888 requirió la negociación de los propietarios de las fábricas, quienes solían considerar al agua como bien privado. Así, argumenta que si bien la legislación -la cual concedió al Estado la capacidad de otorgar concesiones federales para el uso del Atoyacfue importante para el establecimiento de La Covadonga, no fueron eliminadas las prácticas tradicionales de negociación entre los usufructuarios del río.

(Aprovechamientos industriales del agua, industria textil, río Atoyac, José Díaz Rubín, Puebla)

\section{INTRODUCCIÓN}

uando José Díaz Rubín fundó La Covadonga el 15 de octubre de 1897, puso en operaciones la última fábrica textil del corredor industrial del Atoyac, en los límites de los estados de Puebla y Tlaxcala. A partir de aquel año, un conjunto de factorías de hilados, tejidos y estampados de algodón se ubicaban siguiendo la corriente del río, que corría al oriente de la capital poblana después de atravesar el sur del estado de Tlaxcala. Además de estar inte-

*sergiofrosas@yahoo.com.mx 
gradas económicamente a la Angelópolis, pertenecer a su elite económica y dedicarse al mismo ramo productivo, las fábricas compartían el aprovechamiento del Atoyac como la fuente de energía para su funcionamiento, gracias al establecimiento de presas, infraestructura hidráulica e incluso plantas de energía hidroeléctrica que garantizaban el continuo funcionamiento de la maquinaria industrial a partir de la corriente fluvial. Así, a partir de 1897, el corredor industrial del Atoyac conformado por 13 factorías textiles, en Tlaxcala: El Valor, La Tlaxcalteca y La Josefina; y en Puebla, La Covadonga, La María, La Constancia, La Economía, La Beneficencia, El Patriotismo, La Independencia, San Juan Bautista Amatlán, El Molino de Enmedio y Mayorazgo, véase mapa 1.

El estudio de la industria textil poblana no es nuevo. Diversos trabajos han hecho hincapié en su importancia, es uno de los temas más fértiles de la historiografía regional. No es un hecho casual: en su trabajo pionero en torno a esta temática, Jan Bazant mostró que la manufactura textil en Puebla surgió en el siglo XVI, convirtiéndose en la centuria siguiente en el centro de la industria algodonera de la Nueva Espańa, gracias a la abundante mano de obra habituada a su trabajo y a la técnica importada por los colonos españoles (Bazant 1964a). Ya a mediados del siglo XVIII se trataba de una industria consolidada, que en 1835, gracias al afán industrializador de Estevan de Antuñano, inició su mecanización con la fundación de La Constancia Mexicana, la primera fábrica textil del centro del país, que arrancó con 2,500 husos (Ventura 2011, 29).

A partir de entonces, aprovechando el río Atoyac se estableció en Puebla tecnología reciente importada de los Estados Unidos, que gracias a la energía hidráulica permitía economizar gastos en el hilado y expandir la producción, destinada al mercado local y regional (cf. Thomson 1999). Gracias a ello, entre 1835 y 1845 , en la década que Thomson llama de industrialización precoz, se establecieron 8 fábricas textiles en haciendas y molinos establecidos en la ribera del Atoyac, por lo que en 1843 más de la mitad de las mantas de algodón en el país se fabricaban en Puebla, a pesar de las dificultades para obtener la materia prima (Bazant 1964b). Según una estadística del Ayuntamiento de Puebla, en las siete fábricas poblanas en 
Mapa 1. Las fábricas textiles del Atoyac en un plano de Puebla, ca. 1900.

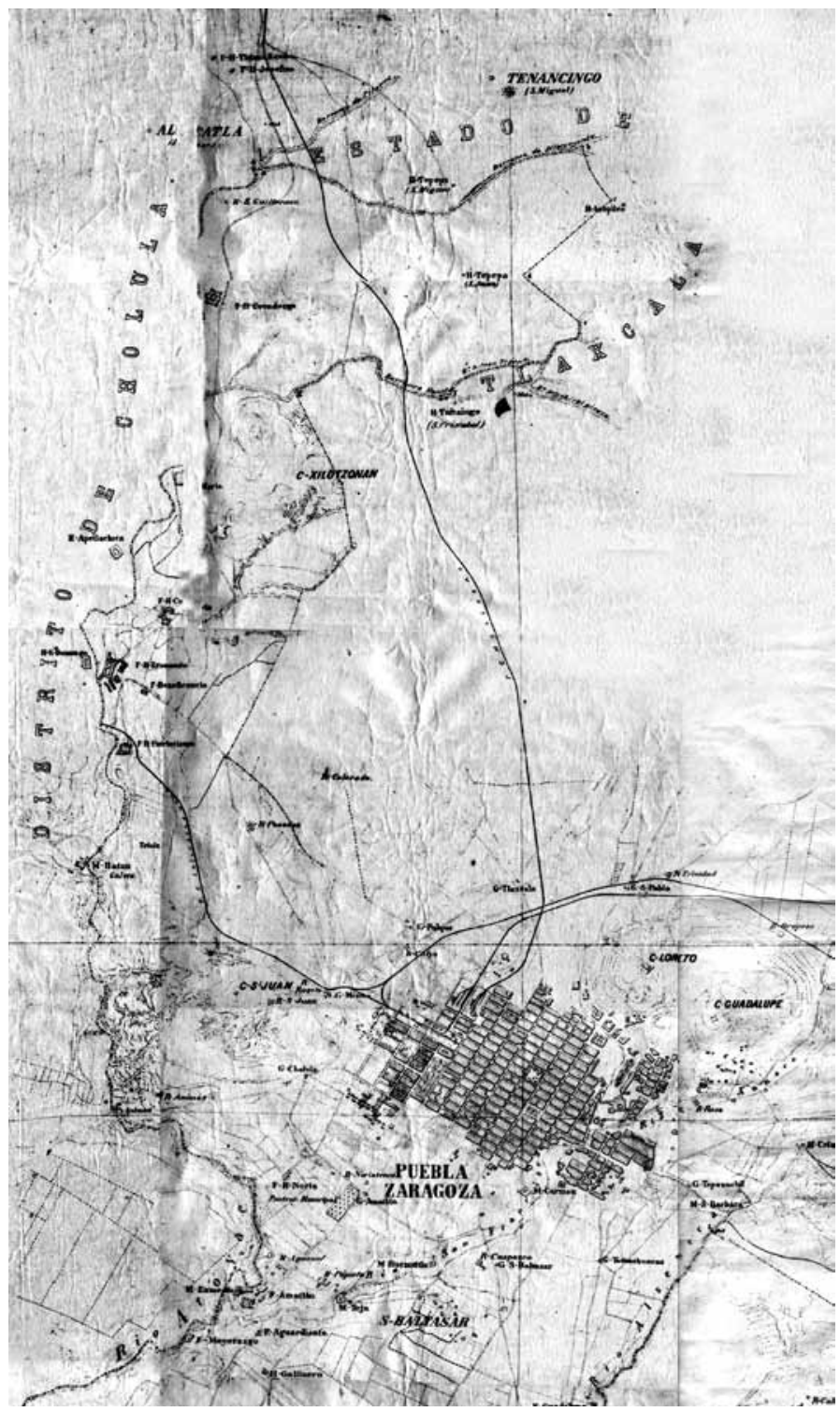

Fuente: Archivo Histórico del Ayuntamiento de Puebla, Planos, caja 1, núm. 37. "Plano del municipio de Puebla, sin fecha”. 
1852 en el Atoyac -La Constancia Mexicana, La Economía Mexicana, El Patriotismo Mexicano, El Molino de Enmedio, San Juan Bautista Amatlán y El Mayorazgo- funcionaban 29,127 husos y 468 telares. ${ }^{1}$ La segunda ola de fundaciones llegó hasta el porfiriato, en el sector norte del Atoyac, en los límites de Puebla y Tlaxcala. En este estado se fundaron La Josefina y La Tlaxcalteca en 1883 y 1884 respectivamente, La María en 1896 y, finalmente, La Covadonga en 1897 , de la que me ocupo, que significaron un segundo salto tecnológico en la región no sólo por la implantación de fábricas más grandes y modernas, sino por la instalación de energía hidroeléctrica aprovechando el río.

Las problemáticas de la industria textil poblana han sido abordadas a partir de dos corrientes historiográficas. Por un lado, a partir del libro de Juan Carlos Grosso (1984), se ha perseverado en el estudio de los trabajadores, destacándose su conformación como clase y su participación en movimientos sociales, sea a partir de una región como Atlixco o a partir del estudio de una factoría en particular, como La Constancia Mexicana (Gómez Álvarez 1989; Estrada Urroz 1997; Gamboa Ojeda 2001; Ventura Rodríguez 2011). Por otro, a partir del trabajo de Leticia Gamboa (1985), se ha estudiado la trayectoria de los empresarios y sus inversiones, subrayándose en esta línea los estudios de caso (Gamboa y Estrada 1986; Aguirre Anaya 1987; Torres Bautista 1994). Por su parte, Guy Thomson y Coralia Gutiérrez han hecho intentos de síntesis entre historia social y de la industria, tanto para la primera mitad del siglo XIX como para los primeros años del xx (Thomson 2002 y Gutiérrez Álvarez 2000).

En lo que se refiere a la historiografía sobre el agua en Puebla, se ha privilegiado el estudio del abasto y la distribución del agua potable en la capital (Loreto López 1994; Birrichaga Gardida 2003; Salazar Exaire 2006), y se ha aprovechado la abundante documentación para realizar estudios de las relaciones sociales en la Puebla virreinal, teniéndose como protagonistas al ayuntamiento y a las órdenes religiosas (Carabarín Gracia 2000; Loreto López 2000).

${ }^{1}$ AHAP, Documentos de Cabildo, vol. 119, ff. 376-382. La estadística no incluye El Valor, fundada en 1839 , por ubicarse en territorio tlaxcalteca. 
Aportaciones recientes miran al líquido como clave para estudiar la historia ambiental (Loreto López 2008; Loreto López, coord., 2009). Por otra parte, existe ya un conjunto de estudios sobre diversas regiones del estado, como Tehuacán e Izúcar, centradas en las relaciones de poder entretejidas con el dominio de los recursos hídricos (Salazar Exaire 2000; Gómez Carpinteiro 2003; Mendoza García 2005; Fitting 2007; Rosario Jiménez 2008).

Respecto a la relación entre agua e industria, Alberto Carabarín estudió el control que el ayuntamiento poblano del siglo XvI sostuvo sobre los ríos, como motores para el establecimiento hispano en el antiguo valle del Cuextlacoapan. Al hacerlo tocó el establecimiento de los molinos en las riberas angelopolitanas como antecedente del futuro desarrollo industrial de la región (Carabarín Gracia 2000). Un aporte reciente en torno al uso industrial del agua del Atoyac es el artículo de Evelyne Sánchez Guillermo (2008), desarrollado a partir del estudio de los empresarios y sus redes en la temprana industrialización de Puebla. Para la autora, a partir de 1835, los industriales se apropiaron del extremo oriental del Balsas en detrimento de la agricultura, al mismo tiempo que se organizaron de acuerdo a la ubicación de sus propiedades con respecto a la corriente del río. Desde su perspectiva, a lo largo del siglo XIX, el agua fue una fuente de conflicto debido a la ausencia de un marco jurídico y a la presión que la industrialización introdujo sobre la corriente hidráulica (Sánchez Guillermo 2008, 118).

El caso de Atlixco es bien conocido. Mariano Castellanos sostiene que la industrialización de aquella región del suroeste poblano tuvo como elemento central la abundancia y calidad del agua, aprovechándola como generadora de fuerza motriz o eléctrica y en el proceso productivo, lo que llevó a que a finales del siglo xix existieran en torno al Cantarranas 7 fábricas textiles (Castellanos 2009, 46-54). Concentrado en el caso de Metepec, el autor demuestra que la abundancia de líquido y la construcción de una infraestructura hidráulica basada en presas y canales de conducción al centro productivo era vital para el buen funcionamiento de las fábricas, ya que a partir de 1890 la base de todo proyecto industrializador era garantizar el suficiente suministro hídrico para la producción de energía 
hidroeléctrica (Castellanos 2009b, 169-193). Por su parte, Rocío Castañeda González sostiene que la creciente demanda por el agua en Atlixco producto de la industrialización y la agricultura capitalista fue el detonante de conflictos por el recurso hídrico en la zona central y suroeste del estado de Puebla durante el porfiriato, particularmente en torno al río Nexapa, que, sin embargo, no cuestionaron los repartimientos coloniales de agua. Estos últimos, que fungían como la base de los acuerdos entre regantes, fueron lo bastante flexibles hasta el cambio total de las condiciones para los cuales fueron diseñados (Castañeda González 2005) e incluso fueron ratificados por la autoridad federal, como ocurrió en el caso del corredor industrial del Atoyac en 1906, según dispuso el ingeniero Ramón de Ibarrola.

Interesada también en el corredor industrial del Atoyac, María Teresa Ventura (2009) estudia, por su parte, el corredor industrial del Atoyac como el elemento que permitió la innovación tecnológica en la producción textil poblana a lo largo del siglo xIx, y destaca, primero, la importancia del río como fuente de energía hidráulica y después hidroeléctrica. Este cambio tecnológico, sostiene Ventura, fue un segundo salto tecnológico comparable a la década de industrialización precoz: además de permitir la fundación de las fábricas del norte del corredor y un consiguiente aumento en el número de husos y telares, el cambio central de las fábricas del Atoyac fue la introducción de turbinas e hidroelectricidad en sustitución de las ruedas hidráulicas. Ello exigió la construcción de presas y plantas productoras de electricidad, permitiendo entre otros aspectos la introducción del blanqueo y el estampe de telas (Ventura 2009, 46). La Covadonga es un buen ejemplo de este proceso. Amén de estas líneas, Rosalina Estrada realizó un primer acercamiento a la fábrica, interesada en la modernización tecnológica de mediados del siglo xx y su relación con los trabajadores (Estrada Urroz 1986). En su trabajo, Estrada considera a la fábrica como una de las más grandes de la entidad, tal como lo señala Leticia Gamboa en 1906 (Gamboa Ojeda 1985, 124). Si bien, en 1910, alcanzó la cifra máxima de 1,000 obreros dedicados al hilado, tejido y estampado del algodón, en 1897, el año de su fundación, contaba con 360 operarios de un total de 2,257 , concentrando a casi $16 \%$ de la fuerza productiva en 
las fábricas textiles del municipio de Puebla. Sólo era superada en número de operarios por La Economía que reunía a 450 trabajadores, y superaba por poco a El Mayorazgo que tenía 350. Su producción alcanzó en 1906, primer año del que tenemos registro, 1,116,416 pesos (Contreras Cruz 1986, 174-176). Funcionaba desde fines de siglo con 500 telares, según declaró el mismo Díaz Rubín al gobierno federal.

A partir del caso de La Covadonga, este trabajo se suma a los estudios que analizan la relación entre agua e industria en México desde una perspectiva regional. Existen ya valiosos antecedentes en este sentido. En un trabajo clásico, Dawn Keremitsis (1973) señaló la importancia del líquido como fuerza motriz en la industria textil del siglo XIX, si bien esta aportación pionera pasó largo tiempo desapercibida. No fue sino hasta la década de los noventa cuando, con el auge de los estudios sociales del agua, Blanca Estela Suárez (1997 y 1998) mostró de nueva cuenta la relación entre agua e industria, por lo menos en el centro del país. Suárez apuntó que las fábricas, sobre todo las textiles, dependieron del agua desde su establecimiento en 1835 , pues la nueva maquinaria era impulsada por fuerza hidráulica. Debido a esto, los ríos fueron los lugares preferidos para la industrialización. El caso que estudiamos, el del corredor del río Atoyac, es una muestra clara de este fenómeno. La otra aportación fundamental de los trabajos de Suárez Cortez fue mostrar que este desarrollo dependiente de corrientes fluviales generó un creciente conflicto por el control del agua, pues los industriales, necesitados de mayores recursos hídricos, debieron enfrentarse entre ellos mismos, además de afrontar ayuntamientos y agricultores para tener acceso a la mayor explotación del recurso (Suárez Cortez 1997, 2628 y 89-90). Por su parte, Diana Birrichaga (2008), al insistir en que el agua devino en un "recurso estratégico" para la industrialización del país entre los siglos XIX y xx, mostró en un trabajo reciente el impacto ambiental que tuvo la industrialización en México, sea por el incremento en la demanda del agua o por la contaminación del líquido debido a la propia actividad productiva.

Así pues, en este trabajo busco contribuir a la reflexión sobre el agua y la industria, a partir de un caso extramuros de la ciudad de 
Puebla. Tengo como objetivo analizar la estrategia implementada por José Díaz Rubín para obtener el usufructo del río Atoyac, con miras a establecer La Covadonga y aprovechar el líquido como fuente de energía hidráulica e hidroeléctrica. El caso es valioso puesto que, al constituir la última fábrica textil en el corredor, su propietario debió negociar con los demás industriales para poder utilizar esta fuente de energía natural. Al mismo tiempo, lo tardío de la fundación le permitió aprovechar la legislación de 1888, que inició el paulatino control de los aprovechamientos hidráulicos por parte del gobierno federal (Aboites 1997). El marco cronológico responde al proyecto del empresario asturiano, desde el inicio de sus operaciones en la zona hasta la fundación del espacio industrial.

Argumentaré que si bien la legislación de 1888 fue importante para el establecimiento de La Covadonga, al otorgar concesiones federales para el uso de las aguas del Atoyac, no por ello eliminó las antiguas prácticas de negociación entre los usufructuarios del río, quienes asumían al líquido como un bien privado. En este sentido, retomo lo seńalado por Luis Aboites y Martín Sánchez, quienes apuntan la necesidad de hacer una historia del agua que combine la mirada nacional, a partir de 1888 , con los estudios locales, para poder comprender la compleja situación creada por el fortalecimiento del Estado nacional y su coexistencia con una tradición ligada al dominio del agua por ayuntamientos y gobiernos estatales (Aboites 2005, 25-31 y Sánchez Rodríguez 2002, 177-183). Del mismo modo, busco mostrar la importancia que los industriales dieron al líquido para el desarrollo de la industria en Puebla, y señaladamente en el corredor industrial del Atoyac. Esto hizo posible que el control de este recurso fuera espacio para la negociación y el conflicto. Señalo, además, la importancia del dominio de la tierra para alcanzar el control sobre el agua.

En suma, este artículo ilustra, a partir de un estudio de caso, la forma en que un nuevo interesado en el uso industrial de las aguas del Atoyac consiguió hacerse de un amplio espacio físico para la instalación de una fábrica textil en el corredor industrial y, más tarde, cómo obtuvo con relativa facilidad concesiones del gobierno federal para la construcción de infraestructura hidráulica y para el 
uso del líquido fluvial. Por último, ilustra cómo los usuarios que le antecedían en el aprovechamiento del Atoyac -en este caso, los dueños de las fábricas La Josefina y La Tlaxcalteca- sólo accedieron a que José Díaz Rubín utilizara sus concesiones federales tras un acuerdo privado protocolizado ante notario. Así, estas líneas documentan en detalle la forma como los usuarios interesados en el aprovechamiento industrial del Atoyac sólo fueron capaces de utilizar sus concesiones federales tras una negociación con los demás usuarios del río, como ocurría desde la instalación de las primeras fábricas textiles del corredor.

Para sostener mi hipótesis, he dividido el artículo en tres partes. En la primera, me ocupo de la conformación del corredor industrial del Atoyac, subrayando la importancia del río para el establecimiento de fábricas textiles. En concreto, destaco que a partir de su cauce se desarrolló un corredor industrial, en los límites de los estados de Puebla y Tlaxcala, en dos momentos del siglo XIX, creando así un corredor que tenía en común la mecanización del hilado y tejido de algodón, el aprovechamiento de la corriente fluvial para la generación de energía y su integración económica a la ciudad de Puebla. En segundo lugar, apunto los elementos que hicieron posible a José Díaz Rubín dominar el extremo norte del río Atoyac y, por ende, establecer La Covadonga. Me concentro en los contratos y acuerdos signados con los dueños de las fábricas ubicadas en la zona norte del corredor. En tercer lugar analizo los acuerdos y las concesiones, locales y nacionales, que permitieron a este industrial obtener el dominio del agua que garantizó el funcionamiento de la fábrica.

El artículo se basa en fuentes de archivo. Los acuerdos entre particulares, así como las ventas de tierra y concesiones de agua, las recabé en el Archivo General de Notarías del Estado de Puebla (AGNEP). Tras la concreción de un acuerdo entre los usuarios del río -todos ellos propietarios de fábricas textiles o haciendas-, su protocolización ante notario era la seguridad de que sería cumplido y adquiría fuerza de contrato legal entre las partes interesadas. Así, los libros notariales fueron especialmente útiles no sólo para conocer las compras de José Díaz Rubín con miras a fundar La Covadonga, sino para conocer la práctica de los acuerdos privados entre usuarios 
del Atoyac. Las concesiones federales, que Díaz Rubín recibió con relativa facilidad, las encontré en el Archivo Histórico del Agua (АНA). Los expedientes de La Covadonga, como del resto del corredor del Atoyac, registran no sólo la petición y la concesión, sino el intercambio de correspondencia entre los particulares y la Secretaría de Fomento, lo que permitió conocer en detalle la negociación realizada para alcanzar la aplicación de la ley de 1888 . Por último, recurrí al Archivo Histórico del Ayuntamiento de Puebla (AHAP) para conocer algunos datos de las fábricas textiles anteriores a la fundación de La Covadonga.

\section{La industria teXtil en el AtoyaC}

El corredor industrial del Atoyac surgió gracias a los recursos hidráulicos de la región. El río, del mismo nombre, que lo origina nace en la frontera de Puebla con el Estado de México, en la Sierra Nevada. En el periodo que estudio, el río pasaba por el antiguo distrito de Zaragoza de Tlaxcala, para después entrar al valle de Puebla, cruzar por el costado oriental de la capital del estado, de norte a sur, y recorrer después los valles de Atlixco, donde también fue aprovechado por las industrias textiles, y también a Izúcar y Chiautla, donde benefició las haciendas e ingenios cañeros. El uso del afluente en las manufacturas está documentado desde el siglo xvI; fue "conquistado" desde 1541, cuando el molino de Amatlán fue fundado a su vera. ${ }^{2}$ Éste formaba parte de un proyecto más amplio, impulsado por el ayuntamiento de Puebla, que buscaba desarrollar un espacio tecnológico en la nueva ciudad dedicado a la molienda de trigo, aprovechando el agua del río San Francisco, afluente del Atoyac (Carabarín Gracia 2000, 120). Así, el Atoyac fue empleado para activar la rueda hidráulica de los molinos de trigo (Salazar Exaire 2006, 42). El Atoyac y su afluente, el río de San Francisco, rodeaban el espacio urbano angelopolitano, constituyendo, por sí mismos, "zonas con características naturales diferentes", tanto por la humedad y fertilidad que otorgaban al terreno,

\footnotetext{
${ }^{2}$ AHAP, Actas de Cabildo, libro 4, junio de 1541, f. 103.
} 
como por la posibilidad de producir energía a través de sus cauces (Salazar, Peña, Gómez y Peña 2007, 18).

Como ya he señalado, el corredor industrial del Atoyac, caracterizado por reunir en su ribera a fábricas de hilado, tejido y más tarde estampado de algodón, surgió en dos oleadas de industrialización en el primer y último tercio del siglo xIx. La primera, entre 1835 y 1843, inició gracias al espíritu emprendedor de Estevan de Antuñano, quien fundó en 1835 la primera factoría mecanizada de hilados de algodón, La Constancia Mexicana. Gracias a su despegue inicial y a una intensa campaña a favor de la industrialización del sector como un paliativo para la recesión que sufría la economía poblana emprendida por el propio Antuñano, en 1843, existían ya siete fábricas textiles en la ribera oriental del río Atoyac, instaladas la mayoría en antiguos molinos trigueros, cuyos antecedentes podían remontarse al siglo Xvi. Por orden de fundación, en 1843, las fábricas textiles del corredor eran, además de La Constancia, San Juan Bautista Amatlán (1838), El Patriotismo (1839), El Valor (1839), El Mayorazgo (1841), El Molino de Enmedio (1842) y La Economía (1843). A ello había que sumar dos fábricas no textiles: la Fundición de Panzacola, establecida en 1838, y que se mantuvo en el giro hasta bien entrado el siglo xx ( $c f$. Gamboa y Santibañez 1994), y la fábrica de papel La Beneficencia, fundada en 1836, pero que en la década de 1860 se transformó también en fábrica de hilados y tejidos de algodón (Torres Bautista 1995, 139-158).

El segundo periodo de industrialización se dio en las décadas de 1880 y 1890 . Así, en 1883 se fundó La Josefina, quedando anexa La Tlaxcalteca al año siguiente; en 1896, inició operaciones La María y, finalmente, La Covadonga inició sus operaciones en 1897. A diferencia de las fábricas textiles instaladas durante la temprana oleada de industrialización, las surgidas en este momento crearon edificios industriales ex profeso y aprovecharon el río como generador de energía hidroeléctrica, dando paso a un importante paso tecnológico en el aprovechamiento del río Atoyac. En suma, el corredor industrial del Atoyac se formó en dos periodos, el primero entre 1835 y 1843 y, el segundo, entre 1883 y 1897. En las riberas del afluente se desarrolló una zona industrial que, siguiendo el curso del río de 
Croquis i. Fábricas y haciendas en el Corredor Industrial del Atoyac, 1897.

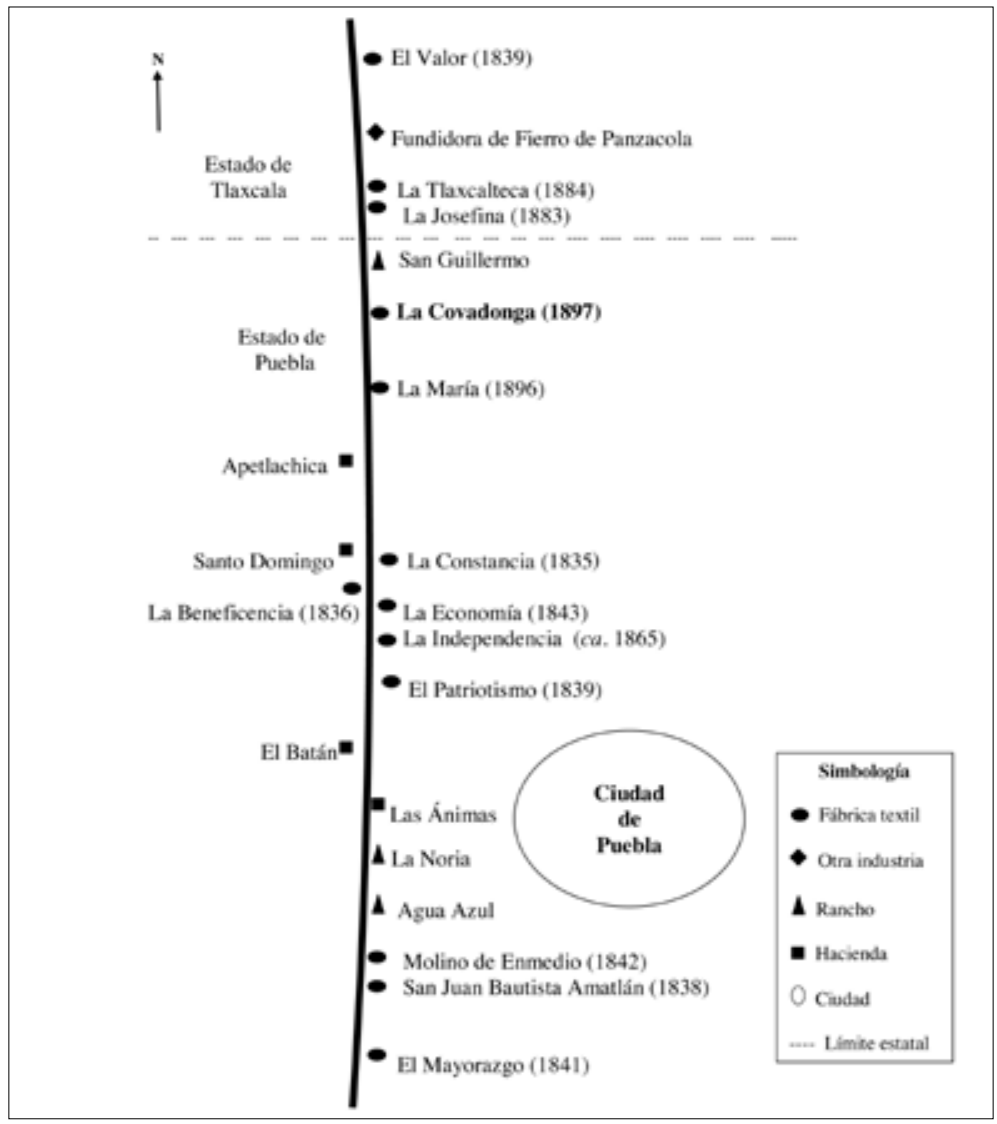

Fuente: Elaboración propia con base en los planos tipográficos del municipio de Puebla ca. 1910 y 1933, en Archivo Histórico del Ayuntamiento de Puebla (AHAP), Planos, caja 1, planos 22 y 37.

norte a sur, se caracterizó por su especialización en el hilado, tejido y estampado de algodón; el aprovechamiento del Atoyac para impulsar la maquinaria industrial y su ligazón económica con la región poblana, pues su producción se destinaba particularmente a aquel mercado. En la continuidad del corredor industrial fue especialmente importante el tránsito tecnológico de energía motriz a 
hidroeléctrica, lo que permitió la modernización de la industria a fines de siglo. La creciente presión sobre el recurso hídrico produjo que su aprovechamiento fuera una constante fuente de acuerdos y disputas a lo largo del siglo XIx. Esto se debió a que, siguiendo a Aurora Gómez-Galvarriato, la producción dependía de la fuente de poder empleado: aquel que utilizaba energía humana tenía valor de producción de 2.75 pesos por cada peso invertido en mano de obra; quien empleaba energía de vapor, 3.05 pesos; el costo con mulas era de 3.43; y los que usaban agua producían 4.27 por cada peso invertido (Gómez Galvarriato 1999, 158). He ahí una de las razones primordiales del porqué depender del río: por el buen nivel de ganancia.

Estevan de Antuñano es el responsable del inicio del corredor. El industrial veracruzano compró desde 1831 la hacienda y molino de Santo Domingo para establecer La Constancia, la primera fábrica textil de Puebla y del centro del país, fundada, como ya he comentado, en 1835. De acuerdo con cálculos de Evelyne Sánchez, aquel ańo, el precio del lugar apenas dependía del agua: los surcos representaban $30 \%$ del precio total del terreno, 18 mil pesos (Sánchez Guillermo 2003, 200). Sin embargo, en 1853 el agua era ya $43.24 \%$ de su valor; era el uso industrial $22 \%, 31,275$ pesos. Para mediados del siglo XIX ya había una presa sobre el río Atoyac, cuyo valor ascendía a los 3,992 pesos, lo que hacía que el agua y las obras hidráulicas fueran $68.3 \%$ del valor del inmueble. ${ }^{3} \mathrm{El}$ agua fue desde entonces punto central de los contratos. A través de la batalla por el río Atoyac se puede ver cómo éste fue central para el desarrollo industrial de la región.

El valor que Antuñano otorgó al líquido es notorio desde 1836. En aquel año, vendió a Dionicio Velasco, Ciriaco Marrón y Andrés Vallarino terrenos y agua para instalar "El Patriotismo", otra de las tempranas fábricas textiles, por 297,922 pesos. El artículo tercero del contrato estipuló que el agua utilizada por El Patriotismo desde entonces pasara a manos de "Velasco y Compañía". Además, se le permitiría tomar la necesaria para producir energía y mover la ma-

${ }^{3}$ AGNEP, notaría 1, notario Ángel Guevara Figueroa, libro de 1865, f. 159v. 
quinaria. ${ }^{4}$ En 1865, el agua representaba $50.3 \%$ del valor de la antigua hacienda de Santo Domingo y el rancho de Moratilla, gracias a la inversión industrial.

Otra de las fábricas tempranas se ubicaba al extremo sur del corredor industrial del Atoyac: San Juan Bautista Amatlán. En la década de los cuarenta se establecieron ahí otras dos fábricas textiles: El Molino de Enmedio y Mayorazgo, en 1841, esta última gracias a la rueda hidráulica que movía el molino de trigo. Este polo, ubicado hoy en la zona sur de la ciudad de Puebla, data del establecimiento de San Juan Bautista Amatlán, en 1838. Desde 1837 se incluyó en el contrato de venta del molino -que funcionaba desde, por lo menos, 1541- la venta de las aguas utilizadas para mover tres piedras de molienda. ${ }^{5} \mathrm{El}$ fin de la compra era establecer una fábrica de hilados y tejidos de algodón, cuya maquinaria fue importada por Antonio de Haro y Tamaríz y Estevan de Antuñano desde Estados Unidos. Es notorio que entonces apenas se mencionó el agua, pero a mediados de siglo ésta era fundamental, según deja ver un acuerdo protocolizado ante notario.

Así, para mediados de siglo, los industriales eran conscientes de que el río era fundamental para la industria textil establecida en su vera. Esto generó la saturación de usuarios del río, algo que ocurrió también en Atlixco, en el aprovechamiento del Nazas y en los ingenios azucareros de Morelos (Valladares de la Cruz 2003; Castañeda González 2005; Romero Navarrete 2008). El Atoyac se veía más demandado no sólo por la cada vez mayor cantidad de inversionistas, sino porque éstos exigían continuamente más volumen de agua para la producción de sus fábricas. Como mostraré adelante, un medio para solucionar el problema fue el acuerdo entre usuarios. El otro fue la inversión en maquinaria de vapor, para sostener la producción textil en caso de que el abasto de agua deviniera insuficiente ante la excesiva demanda. Tal fue el caso, por ejemplo, de Bergés de Zúñiga una vez que se hizo de la propiedad de La Constancia Mexicana (Sánchez Guillermo 2008, 117-118).

\footnotetext{
${ }^{4}$ AGNEP, notaría 1, notario José María Torres, libro de 1845, 397v-401 fs.

${ }^{5}$ AGNEP, notaría 5, notario Patricio Carrasco, libro de 1896, 4 de agosto, f. 63
} 
En 1868 se puede documentar otro caso, el del acuerdo y negociación entre usuarios. Aquel año algunos dueños de fábricas de la zona buscaron participar de la posesión de algunas aguas, debido a un pleito de 1865 entre los dueños de las fábricas "El Mayorazgo" y de "Enmedio", Furlong y Quijano, por la utilización de la fuerza hidráulica (Rivero Quijano 1990, I, 189-191). Se creó una sociedad entre los dueños de las fábricas del "Molino de Enmedio", "La Teja" y "San Juan Bautista Amatlán”, para el uso de las aguas de los ríos Atoyac y San Francisco. Ya se habían construido "obras para la conducción de las aguas". Los miembros tenían derecho a usar las aguas "como agente mecánico para el movimiento de sus establecimientos industriales", sin poder consumirla o cambiar su curso, estipulándose que una vez que hubieran sido aprovechadas, deberían dejarse correr íntegramente. El valor de las aguas fue estipulado en 16,852 pesos. ${ }^{6}$ Como se ve, el acuerdo se hacía entre particulares y se ratificaba ante notario. El elemento central radicaba en que los dueños de las fábricas se comprometían a usar el agua del Atoyac sólo como productor de energía hidráulica, y se impedían utilizar el agua para riego o retenerla para cualquier otro uso. Lo mismo exigían a sus pares.

Este tipo de acuerdos hizo que los dueños de las fábricas fueran cada vez más puntuales en el control sobre el agua y su derecho a usufructuarla. El ejemplo del Molino de Enmedio es revelador. Entre 1855 y 1856, el dueño de éste, Cosme Furlong, empezó a medir el volumen de agua que entraba a su propiedad. Calculó que cada segundo el Atoyac llevaba consigo ocho mil litros, que a mediados de siglo eran suficientes. Sin embargo, para 1873, Furlong debió suscribir un acuerdo con Pedro Bergés de Zúñiga, dueño de La Constancia, para poder utilizar "18 surcos de agua tomada" de los derrames de la fábrica de la Noria, para llevarlos al Molino de Enmedio utilizando un acueducto. Es evidente que, si bien gracias a su posición entre el Atoyac y el San Francisco, la fábrica de Furlong podía utilizar ambas corrientes, con el paso del siglo XIX el agua no

${ }^{6}$ AGNEP, notaría 5, notario Gregorio Sandoval, libro de 1868, 30 de octubre, f. 380 . La sociedad se canceló dos años después, en 1870. 
fue suficiente, ya fuera por el crecimiento de la factoría o por la mayor demanda del líquido río arriba. La gran población fabril junto al río para estas fechas afectaba el caudal del Atoyac, pues en 1914 llevaba consigo, al entrar a terrenos del Molino, apenas cinco mil litros por segundo, había perdido en 50 años tres mil litros por segundo. Esto obligó a los dueños de la fábrica a construir una presa que garantizara una caída de casi 10 metros, y a utilizar 400 litros por segundo del río de San Francisco (Gamboa Ojeda 2005, 45-48). Sin embargo, no todas las fábricas tenían acceso a dos grandes ríos para garantizar su abasto de agua.

Otro ejemplo es el de San Juan Bautista Amatlán, el cual revela lo lucrativo que era utilizar la energía hidráulica. En 1878, la fábrica seguía siendo de tamaño medio, pero con gran producción: tenía contratados 85 operarios adultos y 35 niños. Producía mensualmente 4,750 kilos de manta y 935 de hilaza. El valor de su edificio era de 55 mil pesos y el de su maquinaria de 30 mil. Sus 40 caballos de fuerza eran suministrados por energía hidráulica, lo que le permitía consumir al año 7,800 quintales de algodón y mantener activos 120 telares (Estadística de la República 1880, snp). Seis años después, en 1884, Amatlán producía 31,200 piezas de manta anuales, con un valor de 109,200 pesos (García Cubas 1888, 26).

Más tarde, en el extremo norte del corredor, en Tlaxcala, se estableció en la ribera del río Zahuapan "La Tlaxcalteca", el 22 de marzo de 1881 . El costo total de la fábrica era de 126,330 pesos. El terreno, la presa y el canal con la construcción estaban valuados en 76,571 pesos, mientras que la maquinaria tenía un valor de 49,759.7 El mismo año se estableció la fábrica que completó la zona tlaxcalteca del corredor: La Josefina, fundada por Santos López de Letona. El agua era utilizada para mover "las turbinas de la fábrica", por medio de un canal creado ex profeso. ${ }^{8}$

Como se ve, en el último tercio del siglo xIx el valor del agua era por sí mismo poco más de la mitad del valor de las fábricas del Atoyac. La importancia que los industriales concedían al líquido estaba $362 \mathrm{v}$.

${ }^{7}$ AGNEP, notaría 5, notario Patricio Carrasco, libro de 1892, 18 de noviembre, f.

${ }^{8}$ AGNeP, notaría 5, notario Patricio Carrasco, libro de 1890, 6 de diciembre, f. 223. 
en función de éste como fuente de energía. Según se deja ver en los contratos, el líquido era considerado una propiedad privada, que al mismo tiempo debía compartirse entre los dueños de las fábricas del corredor. Con esta actitud es notorio el desplazamiento del ayuntamiento en el dominio del agua, que pasó a ser, durante el siglo XIX, un aspecto acordado entre particulares, a través de la validación jurídica de los notarios de la ciudad. ${ }^{9}$ Esto dio pie, además del conflicto, a la negociación.

Para 1895, con el establecimiento de las fábricas del norte del corredor, había en el Atoyac diez centros textiles de medianas y grandes proporciones que compartían, además del ámbito geográfico, la dependencia del agua. Ésta, a su vez, los hacía rentables como para llamar la atención de otros industriales. Uno de ellos fue José Díaz Rubín, quien desde 1889 inició la compra de terrenos con miras a establecer la última fábrica textil del corredor: La Covadonga.

\section{José Díaz Rubín y la fundación de La Covadonga}

Antes de morir en 1903, las principales posesiones de José Díaz Rubín eran el almacén de abarrotes y ultramarinos en la plaza central de Puebla, el ingenio de Atencingo en Izúcar y la fábrica textil La Covadonga. ${ }^{10}$ La riqueza de este industrial asturiano se consolidó a partir de 1878, cuando inició en Izúcar de Matamoros, Puebla, un proceso de acumulación de tierras para alcanzar el dominio del agua. ${ }^{11}$ A partir de aquel año consiguió hacerse de propiedades privadas y comunales, e invirtió en haciendas e ingenios cañeros en

${ }^{9}$ Por ejemplo, el Cabildo del ayuntamiento del 8 de enero de 1847 asentó que los dueños de las fábricas y de La Teja, Amatlán y de Enmedio aprovechaban el agua que servía para el riego del paseo público de San Francisco. Aunque se ordenó una vista de ojos y se corroboró el hecho, el ayuntamiento no pudo hacer nada para evitarlo. AHAP, Actas de Cabildo, 1847, acuerdos del 8 de enero de 1847, f. 9v.

${ }^{10}$ AGNeP, notaría 5, notario Patricio Carrasco, libro del primer semestre de 1907, anexos, f. $265 \mathrm{v}$.

${ }^{11}$ José Díaz Rubín apuntó en un testamento público de 1888 ser originario de Cuenco, Oviedo, y estar avecindado en Puebla. Llegó a México en 1860, a los 14 años, directamente a Puebla, donde se dedicó a servir en la tienda de su tío, León Rubín, hasta fines de la década de 1870, cuando inició su actividad empresarial. AGNEP, notaría 5, notario Patricio Carrasco, libro de 1888, 14 de julio, f. 167v-168. 
aquella región del suroeste del estado de Puebla. Fue en Izúcar donde Díaz Rubín consiguió consolidar su fortuna. En 1894, al adquirir Atencingo, consolidó el emporio azucarero más importante de la región en aquellos años. ${ }^{12}$ Además, poseía y controlaba Rijo y Raboso, ingenios de la misma región, productores de azúcar y aguardiente.

En este apartado pretendo mostrar cómo José Díaz Rubín incursionó en la industria textil en la ciudad de Puebla. Estudiaré el proceso de compra de tierras en los límites de los estados de Puebla y Tlaxcala y su posterior unificación en un solo feudo. Si bien este proceso tenía como objetivo final la fundación de la fábrica "La Covadonga", había uno más inmediato, fundamental para conseguir aquél: el control del agua del Atoyac. Este aspecto lo consideraré más adelante, de manera particular. Por ahora, además del proceso de compra-venta de tierras, me detendré en el establecimiento fabril.

El estudio de La Covadonga es valioso no sólo por tratarse de la última fábrica establecida en el corredor del Atoyac, sino porque ya en 1910 consiguió ser la tercera más importante de la ciudad de Puebla, sólo detrás de La Constancia y El Mayorazgo, con la ventaja sobre éstas de contar con maquinaria más moderna. En ese sentido, ya Rosalina Estrada ha considerado que los años en que la factoría fue propiedad de Díaz Rubín la política empresarial que se implementó en ella fue de continua inversión en maquinaria (Estrada Urroz 1986). La inversión fue importante en su fundación, entre 1889 y 1897 , tanto en maquinaria como en infraestructura hidráulica, así como en 1910, cuando fue modernizada de nuevo y se añadió el estampado al proceso productivo. Visto que las factorías poblanas sólo eran superadas por las gigantes de la región de Orizaba, estaríamos ante una de las más grandes del país, sea por la inversión, por la producción y por el número de trabajadores, por lo menos en el periodo que va de 1907 a 1911, cuando fue atacada por fuerzas zapatistas. En julio de aquel año, Ángel Díaz Rubín sostuvo

${ }^{12}$ AGNEP, notaría 5, notario Patricio Carrasco, primer semestre de 1898, 17 de mayo, f. $210 \mathrm{v}$. 
que las pérdidas por el ataque sumaban 800 mil pesos y generaron la clausura de la fábrica por varias semanas. Entre 1914 y 1917, la fábrica debió cerrar. ${ }^{13}$

De cualquier forma, una descripción de la fábrica, publicada en 1910, festejando los logros de la administración porfiriana en Puebla, nos muestra la importancia que había adquirido bajo la paz del presidente Díaz:

Esta grandiosa fábrica, propiedad de los Sres. Ángel Díaz Rubín Sucs., ${ }^{14}$ se encuentra situada en la parte occidental de la ciudad de Puebla, a 12 kilómetros de distancia, que son recorridos en tranvías de tracción animal. El edificio donde se halla establecida, está siendo objeto de reformas y ampliaciones que demanda el considerable desarrollo que ha adquirido en 12 años que tiene de establecida, y sus departamentos amplísimos, se están dotando de maquinaria moderna, próxima a inaugurarse, para la fabricación de toda clase de telas, finas y corrientes, y otros artículos, como toallas, colchas, etc. [...] Sus 500 telares ocupan un amplio departamento, en condiciones de salubridad e higiene insuperables [...] Toda su maquinaria de estampados y motores es alemana, y la de hilados inglesa, ambas de las más poderosas: 1,000 operarios trabajan en este establecimiento, y su producción media, semanaria, es de 5,000 piezas de géneros de todas clases [...] Los gastos de ampliación del edificio, con otras obras de adaptación y maquinaria, se elevan en la actualidad a $\$ 1,000,000 .{ }^{15}$

¿Cómo consiguió tal producción y éxito? Gracias al control del río, que obtuvo, a su vez, a través de la compra de terrenos cercanos a él

${ }^{13}$ Si bien hay que tomar las cifras con cautela, pues tendían exagerarse, las pérdidas fueron considerables. Sobre el ataque, $c f$. El País, México, 28 de marzo de 1912, p. 1. Un estudio contemporáneo sobre este movimiento, en LaFrance (1983).

${ }^{14}$ José Díaz Rubín había muerto en 1903. La fábrica quedó entonces en manos de sus hermanos León, Francisco, Enrique y Ángel Díaz Rubín, quienes conformaron la sociedad que menciona el texto de 1910. El último de ellos, Ángel, era el único que vivía en México, específicamente en Puebla. Gracias al poder otorgado por sus hermanos, éste conformó la sociedad mercantil. Como había hecho José, la sociedad declaró ser sus más importantes propiedades el ingenio de Atencingo y la fábrica de La Covadonga. AGNEP, notaría 5, notario Patricio Carrasco, 11 de febrero de 1907, f. 78v.

${ }^{15}$ Puebla en el centenario 1910, snp. 
y de la posterior unificación de las tierras en un solo feudo, donde pudo establecer la fábrica.

La primera compra de José Díaz Rubín tendiente a la posterior fundación de La Covadonga se dio el 29 de marzo de 1889, cuando compró a Salvador Furlong el rancho de Guadalupe y un par de terrenos más pequeños, junto al Atoyac. ${ }^{16}$ Meses más tarde concretó el dominio sobre el extremo norte del río cuando compró a Pedro Bergés de Zúńiga, dueño de La Constancia, una fracción del terreno del rancho de Moratilla, anexo a la hacienda de Santo Domingo. ${ }^{17}$ Esta hacienda fue donde se fundó la primera fábrica textil de Puebla, La Constancia Mexicana, en 1835. El rancho tenía una extensión de 597 mil varas cuadradas, con los límites siguientes: "queda limitado al Norte por el Rancho de San Guillermo, conocido también por de Rousset, al Poniente el Río Atoyac, al Oriente por el camino que va para Tlaxcala, y al Sur, por una línea oblicua que atraca actualmente con la presa de la fábrica de la Beneficencia". ${ }^{18}$ Así, Díaz Rubín se instaló junto al primer eje industrial de Puebla. En el contrato consiguió estipular que le era permitido unir su terreno a los que pudiera adquirir más tarde, y que podría darle al rancho o al fundo que conformare el destino que tuviera por más conveniente. ${ }^{19}$

Esta cláusula le evitó cualquier problema al realizar su siguiente compra: la del rancho San Guillermo, que realizó cinco meses después, el 10 de agosto de $1889 .{ }^{20}$ Dicha propiedad estaba dedicada a la producción agrícola y molinera en pequeña escala, en los límites de Puebla y Tlaxcala, pero había adquirido importancia por encontrarse entre dos espacios fabriles que, además, habían creado presas para controlar el agua del río. En su extremo norte se encontraban las fábricas La Tlaxcalteca y La Josefina, y la fundidora de Panzacola, mientras en su extremo sur estaban las fábricas de La Beneficencia,

\footnotetext{
${ }^{16}$ AGNEP, notaría 5, notario Patricio Carrasco, 20 de febrero de 1889, f. 59v.

${ }^{17}$ AGNEP, notaría 5, notario Patricio Carrasco, libro de 1889, 29 de marzo, f. 98.

${ }^{18}$ AGNEP, notaría 5, notario Patricio Carrasco, libro de 1889, 29 de marzo, f. 98v.

${ }^{19}$ AGNEP, notaría 5, notario Patricio Carrasco, libro de 1889, 29 de marzo, f. 99v.

${ }^{20}$ AGNEP, notaría 5, notario Patricio Carrasco, libro del primer semestre de 1907, 21 de enero, f. 44.
} 
La Constancia y El Patriotismo. Los límites que se fijaron al nuevo terreno de Díaz Rubín muestran lo estratégico del paraje: por el oriente estaba en el camino de Puebla a Tlaxcala, al poniente estaba el río Atoyac y al sur una fracción del Rancho de Moratilla que, como hemos visto, era ya propiedad de Díaz Rubín. ${ }^{21}$

La compra del rancho de San Guillermo por el industrial asturiano fue una medida para garantizarse el dominio del agua y la posibilidad de construir una presa para el posterior establecimiento de la Covadonga. A reserva de regresar a esto en el siguiente apartado, Díaz Rubín informó a la Secretaría de Fomento, el 7 de septiembre de 1889, que había comprado el rancho de San Guillermo a los herederos de Antonio Rousset, con su presa, un canal para su antiguo molino de trigo y un aserradero de mármoles, con lo cual evitaba que cualquier paso tendiente al dominio del agua afectara al referido rancho. ${ }^{22} \mathrm{El}$ interés de Díaz Rubín en este punto es notorio en la escritura de venta, otorgada en Puebla el 10 de agosto de 1889. En ella la viuda de Rousset, Josefa Monteja, vendía el rancho de San Guillermo "con todos sus usos, costumbres y servidumbres", y "con la caída de agua que le corresponde". ${ }^{23}$

En 1891, realizó dos compras más. Adquirió dos fracciones de las haciendas de San Miguel Tepepan y San Juan Tulcingo, ubicadas en Zacatelco, Tlaxcala, que eran valiosas por hallarse junto a la barranca natural del Sacro Monte, que a su vez generaba un pequeño islote en el interior del cauce del Atoyac. ${ }^{24}$ Además, adquirió terrenos del pueblo de San Lorenzo Almecatla, en el extremo norte de sus ya extensas propiedades, que lo acercaron a las presas de las fábricas tlaxcaltecas, y le dieron el control de la barranca de Pilares. Por último, para tener mayor control de la zona sur, ya dentro de Puebla, adquirió otra parte del rancho de Moratilla, anexa a la hacienda de Santo Domingo, en junio de 1893. De nueva cuenta, tuvo cui-

${ }^{21}$ AGNEP, notaría 5, notario Patricio Carrasco, libro del primer semestre de 1907, 21 de enero, f. $42 \mathrm{v}$.

${ }^{22}$ AHA, Aprovechamientos Superficiales, c. 4573, exp. 60813, f. 20.

23 "Espediente anexo por Díaz Rubín de compra del Rancho de San Guillermo y posesión de agua”. AHA, Aprovechamientos Superficiales, c. 4573, exp. 60813, fs. 59-59v.

${ }^{24}$ AHA, Aprovechamientos Superficiales, c. 4573, exp. 60813, f. 43v. 
dado de comprar la franja de terreno entre el río y el camino entre Puebla y Tlaxcala. ${ }^{25}$

La adquisición de los terrenos arriba me permite destacar dos elementos. El primero es que en la conformación de este gran feudo en los límites de Puebla y Tlaxcala, Díaz Rubín aprovechó la legislación liberal de mediados del siglo XIX, que a partir de la ley Lerdo, del 25 de junio de 1856, impulsó la "individualización de la tierra", como ha apuntado Antonio Escobar Ohmstede $(2007,28)$. Esto es aún más notorio si revisamos la nómina de los vendedores. Por un lado, José Díaz Rubín adquirió terrenos de pueblos tlaxcaltecas que, si bien utilizaron representantes para cerrar los tratos, tenían como base de su propiedad la tenencia común de la tierra: al vender sus terrenos, dieron paso a la cada vez mayor individualización de la propiedad agraria, y cedieron su propiedad a una nueva generación de empresarios, en su mayoría extranjeros. En la compra de terrenos, pues, Díaz Rubín se aprovechó y colaboró con la individualización y privatización de la tierra, iniciada con la reforma liberal de mediados del siglo XIX.

El segundo elemento también está relacionado con los vendedores. Además de los pueblos, Díaz Rubín compró tierra a otros empresarios, cuyas propiedades estaban ubicadas ya en el estado de Puebla. Los antiguos poseedores eran miembros de una burguesía que, siendo extranjera y propietaria como él mismo, pertenecían a una generación anterior de industriales textiles. Las compras que hizo a Bergés de Zúńiga de tierras y, como mostraré adelante, a Salvador Furlong de aguas, dan cuenta de que Díaz Rubín pertenecía a una nueva generación de empresarios, que había amasado su fortuna a partir de la paz porfiriana y que llegó a la industria textil de Puebla tardíamente. Mientras los apellidos Furlong y Bergés están vinculados a la elite de comerciantes de tradición virreinal en Puebla o a la elite de comerciantes veracruzanos avecindada en la antigua ciudad de los Ángeles durante los primeros años del México independiente, la familia Díaz Rubín pertenece a la oleada de inmigración española llegada tras la restauración de la República (1867). Al

${ }^{25}$ AHA, Aprovechamientos Superficiales, c. 4573, exp. 60813, f. 43v. 
invertir en las ramas de mayor historia en Puebla, este nuevo grupo impulsó la actualización de una tradición manufacturera poblana, la textil, y al mismo tiempo generó su modernización, acorde con los objetivos del régimen porfirista. Ya Dawn Keremitsis ha apuntado que el gobierno de Díaz impulsó la industrialización de la rama textil en México a partir de tres elementos: la concentración de la producción en fábricas cada vez mayores, las grandes inversiones de capital y los inversionistas extranjeros (Keremitsis 1973, 176).

Cuando Díaz Rubín dictó su testamento, el valor de "La Covadonga" era de 266,158 pesos, y estaba valuada en casi el doble del valor 412,206 pesos. ${ }^{26}$ Sin embargo, éste no se cifraba mayormente en los terrenos a pesar de su extensión. Se fincaba en la maquinaria, pero sobre todo en el agua y las instalaciones creadas para su aprovechamiento.

\section{La Covadonga y El AgUA: ENTRE El ACUERdo y EL CONFLicto}

El ya citado ejemplar de Puebla en el Centenario alabó las instalaciones hidráulicas y eléctricas de La Covadonga, en 1910, con las siguientes palabras:

La instalación de su planta eléctrica es digna de todo elogio; está dotada de tres poderosos motores que desarrollan 500 caballos de fuerza, cada uno, distribuidos en un vasto salón, que a pesar de estar situado a una regular profundidad, al descender de él se encuentra inundado de luz natural y perfectamente ventilado. Digno de mencionarse está también, el Departamento de motores que colocados a lo largo de la sala, sirven para mover, cada uno, una sección de maquinaria a la cual están comunicados por modo del sistema de acoplamiento; esta instalación, la primera en la República es de una importante utilidad práctica, pues, por medio de las llaves de que están provistas los motores, se ponen en movimiento o se detienen con suma rapidez, sin que las demás secciones de maquinaria se interrumpan en lo más mínimo. ${ }^{27}$

${ }^{26}$ AGNEP, notaría 5, notario Patricio Carrasco, primer semestre de 1907, 4 de mayo, f. 253.

${ }^{27}$ Puebla en el Centenario, psn. 
Como revela la descripción, la energía dependía por entero del río. Desde el momento en que Díaz Rubín empezó a adquirir terrenos para establecer la fábrica, prestó especial atención a este recurso. En este apartado estudiaré de qué manera el industrial asturiano negoció y obtuvo el dominio del agua del Atoyac para la instalación de La Covadonga, y de qué manera estableció la infraestructura para su aprovechamiento. Como mostraré, dicho proceso está marcado por el acuerdo y la negociación con los demás usuarios del río. Así, Díaz Rubín combinó, para obtener el dominio del agua, tanto la negociación entre particulares, según lo practicado por los industriales desde los orígenes del corredor industrial, como el aprovechamiento de una ley federal: la del 5 de junio de 1888 .

A partir de los contratos notariales es evidente que la principal preocupación de los industriales poblanos establecidos en la zona, por lo menos desde mediados del siglo xIx, era el usufructo del Atoyac en sus establecimientos industriales. Aún más: ya para el último tercio del siglo, el líquido era el elemento más caro, como lo mostró el contrato signado por Díaz Rubín, el 20 de febrero de 1889, con Salvador Furlong, dueño del rancho de Guadalupe. ${ }^{28}$ El documento deja ver que con el dominio del agua venía aparejado el permiso para el establecimiento de centros fabriles.

La escritura detalla la venta que Furlong hizo a Díaz Rubín no sólo de sus terrenos sino también de los derechos que había adquirido sobre el agua del Atoyac al gobierno del estado de Tlaxcala. Éstos consistían en el permiso para utilizar el líquido con el fin de establecer "molino y fábrica", otorgado en marzo de 1883, y en el dominio pleno sobre "una caída de agua proveniente del expresado río Atoyac, en terrenos inmediatos al Rancho de Moratilla, y pertenecientes a la jurisdicción del distrito de Zacatelco" ${ }^{29}$ Furlong no estableció ningún centro productor, pero sí construyó la presa en los márgenes del río y un canal para conducir el agua dentro de su rancho con un pequeño acueducto para el mismo fin..$^{30} \mathrm{El}$ derecho a

${ }^{28}$ AGNEP, notaría 5, notario Patricio Carrasco, 20 de febrero de 1889, f. 59v.

${ }^{29}$ AGNEP, notaría 5, notario Patricio Carrasco, 20 de febrero de 1889, f. 60v.

${ }^{30}$ AGNEP, notaría 5, notario Patricio Carrasco, 20 de febrero de 1889, f. 61. Además, Furlong había adquirido derechos de dominio sobre una cantera en el rancho de Mora- 
ambas construcciones, con los terrenos y las construcciones, fueron adquiridos por Díaz Rubín por 11,100 pesos. La manera en que se distribuyó el valor de la propiedad revela la importancia que había adquirido el agua para cuando Díaz Rubín incursionó en la industria textil. Si por los terrenos pagó apenas 295 pesos, por "la caída, la presa, el canal y el terreno donde se encuentra el sistema de conducción" tuvo que desembolsar 10,805 pesos. $^{31}$

Con esta adquisición, José Díaz Rubín obtuvo el dominio sobre la parte más alta del río Atoyac en la entidad, pues adquirió la primera presa ubicada en territorio estatal. Por ello, el primer paso fue la negociación con los que hasta entonces eran los primeros usuarios del río en Puebla: los dueños de las fábricas de La Constancia y La Beneficencia.

Éste fue posible cuando Díaz Rubín compró a Bergés de Zúñiga una parte del rancho de Moratilla en 1889. En este contrato, de nueva cuenta, el protagonista fue el agua. El artículo tercero del contrato señalaba que, si bien el comprador podía hacer lo que quisiera con el terreno, no debía

estorbar, entorpecer o modificar nunca ni por motivo alguno el uso que de las aguas del río Atoyac hacen o tienen derecho a hacer las fábricas, molinos, o establecimientos industriales que se encuentran río abajo, y especialmente la hacienda de Santo Domingo, propia de los Señores Bergés, y la fábrica de la Beneficencia, que pertenece a Don Juan Matienzo, pues queda pactado de modo expreso, que aunque sirviéndose de la presa recientemente construida en el Río Atoyac, que atraca en punto del terreno que ahora se vende, y se marca con el nombre de "Presa Moratilla", se aprovechará para algún establecimiento industrial la cuida que las aguas del río puedan tener allí, tal aprovechamiento se limitaría a emplearlas sólo como motor, y éstos, sin detener ni alterar, para nada su curso, ni disminuirlas en cantidad, ni por marca alguna, ni desviarlas, sino dentro del terreno adquirido, y esto haciendo siempre que vuelvan a su cauce, precisamente antes de la presa de "La Beneficencia", de modo que ya a ella

tilla, que después emplearía Díaz Rubín para la fachada de su fábrica.

${ }^{31}$ AGNEP, notaría 5, notario Patricio Carrasco, 20 de febrero de 1889, f. 62v. 
lleguen todas las aguas del río, tal y como ahora vienen, quedando así entendido que las aguas ni en todo ni en parte se pueden depositar ni conservarse en jahuey $[s i c]$ o recipiente alguno, ni destinarse a riegos ni mas que a potencia hidráulica. ${ }^{32}$

El agua era un elemento clave para la producción textil en el corredor, tanto como el algodón y la maquinaria, según las condiciones de Bergés, dueño de La Constancia, y de Juan Matienzo, dueño de La Beneficencia. A través del acuerdo garantizaron que seguirían utilizando dicho recurso como hasta entonces, a pesar de la posible fundación de otra fábrica en el Atoyac, cuyo proyecto debió ser ya evidente para ambos industriales. La venta de tierras de Bergés a Díaz Rubín río arriba, en los límites con Tlaxcala, se podría comprender, asimismo, como un mecanismo para forzar el establecimiento de acuerdos en torno al acceso al agua, toda vez que aquel había conseguido ya el usufructo del Atoyac desde febrero de 1889.

Al comprar los derechos de Furlong, Díaz Rubín no sólo tuvo que tratar con los dueńos ubicados en Puebla. Antes bien, con esta adquisición entró de lleno en los conflictos que se desarrollaban en Tlaxcala por el control del Atoyac. Éstos se desataron en 1890, merced a una concentración de industrias en la ribera del río, en el extremo norte del corredor, en los límites de los estados de Puebla y Tlaxcala.

El primer usuario del agua en aquel punto fue la Fundición de Fierro de Panzacola, fundada en 1838. En la década de 1870, Fausto Acedo, a la sazón dueño de la Fundidora, obtuvo un permiso del gobierno del estado para construir una fábrica textil impulsada por el agua del río. Sin poder construirla, su viuda vendió los derechos para tal fin a Santos López de Letona y a Manuel G. Rueda en 1881, quienes instalaron La Tlaxcalteca y La Josefina, además de una presa para el control del agua. ${ }^{33}$ No hubo problemas con este reparto hasta que José Díaz Rivera compró a los hermanos Acedo un terreno junto al río, con derecho a usar el agua que resultara del desagüe de la fundición del fierro y de las fábricas. Aprovechándolas, Rivera esta-

\footnotetext{
${ }^{32}$ AGNEP, notaría 5, notario Patricio Carrasco, 29 de marzo de 1889, fs. 98v-99.

${ }^{33}$ AGNEP, notaría 4, notario Martiniano Porras, libro de 1881, 22 de marzo, f. 206v.
} 
bleció maquinaria para "explotación minera". Gracias a esto, consiguió del estado de Tlaxcala un permiso para construir otra presa, y afectó así la captación hídrica de las fábricas textiles. ${ }^{34}$ Se resolvió construir un canal para la distribución de las aguas.

Estas divisiones y desagües del río debieron preocupar a Díaz Rubín. Al comprar el rancho de San Guillermo, en 1890, Díaz Rubín estableció en la escritura que la posesión también amparaba la caída de agua del Atoyac y el uso de ella..$^{35}$ Lo primero que hizo el asturiano una vez adquirido el rancho fue solicitar permisos para construir una presa más, con canal, en el rancho de San Guillermo, a pesar de que éste ya tenía una. Así, Díaz Rubín devino un industrial más en la búsqueda de controlar el agua de la región.

Sin embargo, es en el método para abrogarse el derecho de las aguas para establecer La Covadonga en el que Díaz Rubín introdujo una novedad sin precedentes en el corredor: introdujo al Estado nacional en las disputas por el Atoyac. Pudo hacerlo gracias a la promulgación de la Ley de Vías Generales de Comunicación promulgada el 5 de junio de 1888, que establecía que los ríos, lagos y canales navegables, y los que servían de límite entre los estados estaban bajo jurisdicción federal. Concretamente, consideró que los mares, canales, lagos y ríos eran "vías generales de comunicación" (Pallares sfe, 338). El expediente, que resultó a favor del empresario asturiano, se conformó en la ciudad de México entre marzo de 1889 y enero de 1890. Su estudio resulta ilustrativo acerca del método utilizado por Díaz Rubín para conseguir el dominio sobre el líquido.

El 18 de marzo de 1889, José Díaz Rubín escribió al secretario de Fomento, Carlos Pacheco, solicitándole se le confirmaran, por parte del gobierno federal, los derechos sobre la caída del río Atoyac que había comprado recientemente a Salvador Furlong, de acuerdo con la ley de 1888. La solicitud argumentaba que se trataba de un asunto de "suma importancia", pues era fundamental "antes de emprender los gastos del reconocimiento o erección de una industria, a la que des-

${ }^{34}$ AGNEP, notaría 5, notario Patricio Carrasco, libro de 1890, 6 de diciembre, $\mathrm{f}$. 223ss.

${ }^{35}$ AGNEP, notaría 5, notario Patricio Carrasco, libro del primer semestre de 1907, 21 de enero, f. 43. 
tino esa caída, tener perfectamente reconocidos los derechos otorgados al seńor Furlong por el estado de Tlaxcala”. ${ }^{36}$ Esto era aún más importante toda vez que pretendía erigir de nuevo la presa para generar la caída, pues había sido arrasada por el temporal de 1887.

Antes de conceder el derecho de usufructo sobre el agua, y por lo tanto el permiso para construir la presa, el gobierno federal pidió el dictamen del ingeniero Ramón de Ibarrola-quien en 1906 entregó al gobierno federal una propuesta para la redistribución del agua del Atoyac-, para decidir sobre el punto. Éste hizo una vista de ojos, el 18 de mayo de 1889 , a partir de la cual concluyó que la construcción solicitada por Díaz Rubín no causaría perjuicios a terceros, como tampoco lo haría el canal de derivación, pues éste no salía nunca de las propiedades del asturiano. Las únicas condiciones necesarias, según Ibarrola, era que el agua del río se devolviera al Atoyac antes de que llegara a la presa del seńor Matienzo, que surtía a La Beneficencia, y que se prohibiera expresamente construir depósitos para guardar o retener el agua, pues ésta debía ser usada únicamente como motor, en beneficio de los demás usuarios. ${ }^{37}$ Para garantizarse la concesión, José compró, en septiembre de 1889, el rancho de San Guillermo, asunto al que ya me he referido arriba, y que tuvo como objetivo conseguir el dominio sobre el agua. Con el dominio del rancho, escribió al secretario Carlos Pacheco el 7 de septiembre. El argumento esgrimido por Díaz Rubín no podía ser más certero:

en la realización de este proyecto [la construcción de la presa] no hay perjuicio alguno de tercero, porque toda la parte del río Atoyac entre la Presa de Rousset y la de la Beneficencia, corre por terrenos que son de mi propiedad, porque en esa misma parte del Río no hay más presas que las de Rousset y de Moratilla que también me pertenecen, y porque el canal corriendo también por terrenos de mi propiedad restituirá las aguas al lecho actual del río, antes de la presa de la Beneficencia con lo que ésta seguirá alimentada como hasta hoy. Por otra parte, las condiciones topográficas son tales, que cualquiera ruptura del canal haría correr las aguas, por mis

\footnotetext{
${ }^{36}$ AHA, Aprovechamientos Superficiales, c. 4573, exp. 60813, f. 1.

${ }^{37}$ AHA, Aprovechamientos Superficiales, c. 4573, exp. 60813, f. 16.
} 
terrenos, para el río. En resumen, la operación será útil para mi, y ni ahora ni nunca perjudicará a los demás ribereños, y bien al contrario, redundará en beneficio de la comarca, por el establecimiento de la fábrica. ${ }^{38}$

Tras algunos meses de estancarse el expediente, Pacheco escribió a Luis Méndez, representante del asturiano en México, que según su opinión particular, debería darse permiso para la construcción de la presa solicitada. ${ }^{39}$

El último paso era que un ingeniero visitara de nueva cuenta el paraje y diera su dictamen sobre el proyecto. Tal acto lo realizó José Pacheco Izquierdo el 7 de mayo de 1890. Éste repitió el dictamen dado en mayo del ańo pasado por el ingeniero Ibarrola: la construcción de la presa no causaría ningún problema a las fábricas La Josefina y La Tlaxcalteca, río arriba, ni a la presa de la Beneficencia río abajo. La caída debía ser de 10 metros 40 centímetros, lo que garantizaría un aforo mínimo de dos mil litros por segundo en tiempo de secas para la fábrica de Díaz Rubín. De hecho, el dictamen de Pacheco Izquierdo otorgaba el dominio y uso de todas las aguas del Atoyac al feudo. La única afectación posible sería para las tierras de riego del pueblo de San Lorenzo Almecatla, pero ésta no tenía importancia, pues "de ese lado del río no se puede usar el agua pues la orilla casi toda está acantilada”, y en la altura exacta donde se establecería la presa y la fábrica "los dos lados del río son propiedad del Señor Díaz Rubín, por lo que es en vano decir algo sobre el particular". ${ }^{40}$

Al fin, José Díaz Rubín obtuvo el 19 de agosto de 1890 una concesión presidencial para construir la presa que solicitó, con un canal para conducir el agua en su propiedad. El mismo mes obtuvo el dominio sobre la barranca del Sacro Monte, que formaba un islote junto al río, que aprovechó para construir la presa que le había sido concedida. ${ }^{41}$

${ }^{38}$ AHA, Aprovechamientos Superficiales, c. 4573, exp. 60813, f. 20.

${ }^{39}$ AHA, Aprovechamientos Superficiales, c. 4573, exp. 60813, f. 61.

${ }^{40}$ AHA, Aprovechamientos Superficiales, c. 4573, exp. 60813, fs. 67- 68.

${ }^{41}$ AGNEP, notaría 5, notario Patricio Carrasco, libro del primer semestre de 1907, 21 de enero, f. 43v. La concesión también se encuentra en AHA, Aprovechamientos Superficiales, c. 4573, exp. 60813, f. 80. 
Quiero insistir en que, a través de este proceso, Díaz Rubín introdujo en sus disputas por el control del agua un elemento externo, dejado de lado hasta entonces: el Estado nacional. Esto fue posible gracias a la formación del concepto de "aguas nacionales", operado desde 1888, ya estudiado por Luis Aboites, que consistió en una nueva noción de propiedad: la que señalaba que el agua es federal, y que podía asimismo ser objeto de grandes negocios. Este proceso, como se ve en el caso que estudio, interrumpió el marco de negociación de usufructuarios del agua durante el siglo XIX, quienes estaban acostumbrados a considerar al agua propiedad privada, dejando de lado al poder público (Aboites 1997, 51). ${ }^{42}$ Sin embargo, la solicitud de Díaz Rubín al gobierno federal no pudo ser aplicada sin más. El Estado nacional aún no tenía tal fuerza. Para ser puesto en práctica requirió de su validación por los medios usuales: la negociación con los demás usuarios y su protocolización ante notario.

La pugna por el control del agua en el extremo norte del corredor industrial, ya en terreno tlaxcalteca, obligó a los interesados a celebrar un acuerdo, firmado el 8 de abril de 1891, entre Díaz Rubín y los dueños de La Tlaxcalteca y La Josefina, Santos López de Letona y Manuel G. de Rueda. En éste, la base de la negociación para el uso del agua ya no es la adquisición de terrenos o el acuerdo privado entre industriales, como el que celebró con Bergés y Matienzo, sino las concesiones federales. ${ }^{43}$ En la partida del 18 de abril de 1891 , lo primero que se enumera son las concesiones del gobierno federal para el uso del agua. ${ }^{44}$

De entrada, José Díaz Rubín hizo asentar los derechos que el gobierno federal le había concedido sobre el agua del río Atoyac. Decía en primer término que el 19 de agosto de 1890, un decreto del presidente Díaz le confirmó la propiedad de la presa del Rancho de San Guillermo, y al mismo tiempo le autorizó construir otra río

${ }^{42}$ Como he señalado, para estas fechas el Ayuntamiento de Puebla había sido desplazado del control de los ríos que rodeaban a la ciudad.

${ }^{43}$ AGNEP, notaria 5, notario Patricio Carrasco, libro del primer semestre de 1891, 8 de abril, f. 172v.

${ }^{44}$ AGNEP, notaría 5, notario Patricio Carrasco, libro del primer semestre de 1891, 18 de abril, f. 172v y ss. 
abajo, en terrenos de su propiedad, para aprovechar el agua y conducirla por medio de un canal hacia el establecimiento fabril que construiría, liberándola de nuevo al Atoyac, en su totalidad, antes de que llegara a la presa de la Beneficencia. Al mismo tiempo, la concesión le prohibía utilizar el líquido para riego en toda su propiedad y construir depósitos para conservarla. La concesión, pues, era sólo para aprovechar el agua como "fuerza motriz en curso constante". ${ }^{45}$

Argumentando que la presa de San Guillermo había sido destruida "por el ciclón de 1888", Díaz Rubín decidió construir otra en el mismo sitio, pero con un metro más de altura, para generar una caída mayor $y$, por lo tanto, tener una mejor fuente de energía. Obtuvo el permiso de la Secretaría de Fomento el 22 de diciembre de 1890 , sosteniendo que

los establecimientos industriales más próximos situados río arriba [...] son las fábricas denominada "La Tlaxcalteca" y "La Josefina" [...] ubicados en el Distrito de Zacatelco, Estado de Tlaxcala, quedando a distancia de más de un kilómetro de la presa vieja de Rousset, y como el lecho del río Atoyac en esa parte de su curso tiene una pendiente de consideración, existe entre el desagüe de las turbinas y la barranca de Pilares cerca de cuya desembocadura se habrá de erigir la construcción indicada, una diferencia de nivel bastante grande para que se pueda elevar un metro más la corona de la nueva presa sin que resulte prejuicio alguno al predio superior, porque esa elevación en nada estorba, la marcha regular de las turbinas, aun en las crecientes extraordinarias. ${ }^{46}$

Por su parte, Santos López de Letona y Manuel G. de Rueda también se ampararon en la ley de 1888 , pero de una forma distinta. No aducían nuevos derechos, sino la confirmación nacional de los derechos adquiridos en 1881 cuando compraron los terrenos para establecer sus fábricas. Así, sólo sostenían que podían aprovechar el agua del Atoyac en el radio de un kilómetro del desagüe de

${ }^{45}$ AGNEP, notaría 5, notario Patricio Carrasco, libro del primer semestre de 1891, 18 de abril, f. 181v.

${ }^{46}$ AGNEP, notaría 5, notario Patricio Carrasco, libro del primer semestre de 1891, 18 de abril, ff. $183 \mathrm{v}-184$. 
sus fábricas, hacia el sur, y que tenían derecho a limpiar el lecho del río para garantizar el buen funcionamiento de sus turbinas. ${ }^{47}$ Letona y Rueda sostuvieron que el intento de Díaz Rubín de hacer más alta la presa de San Guillermo les perjudicaría y, por lo tanto, decían, le pidieron se desistiera de su intento. A cambio, le "ofrecían" reconocer sus derechos y hacer "algunas concesiones”. Díaz Rubín aceptó a cambio de unas condiciones muy favorables para el posterior establecimiento de La Covadonga.

El primer punto de los acuerdos revela la posición ventajosa del asturiano, pues apuntó que se desistía de elevar su presa a pesar de tener permiso del gobierno federal para construirla. ${ }^{48}$ En virtud de ello, Letona y Rueda “accedían a reconocer" como "buenos y legítimos" los derechos de Díaz Rubín sobre la presa y sobre el líquido en sí y, en general "los demás obtenidos del gobierno federal", aceptando la construcción de la presa de San Guillermo con su altura anterior. Asimismo, aceptaron, a petición de Díaz Rubín, que el agua llegara íntegra al asturiano. Aún más, a cambio de no construir la presa, ambos industriales cederían a Díaz Rubín, si así lo quería, el aprovechamiento del desagüe de sus fábricas, incluso antes de volver al río, y construir las obras para ello. Así, Letona y Rueda no sólo renunciaron a la confirmación federal de sus derechos sobre el agua a un kilómetro al sur de sus fábricas, sino que incluso cedieron al asturiano el usufructo de sus propias obras hidráulicas.

El contrato de 1891 muestra cómo la aplicación de la ley del 5 de junio de 1888 en el corredor industrial del Zahuapan-Atoyac no se pudo realizar sin más, sino que requirió el acuerdo y la negociación de los propietarios de las fábricas establecidas en sus riberas, acostumbrados a la negociación particular y a considerar al agua como bien privado. Para su aplicación, las concesiones federales, incluso si no se realizaron tal como estaban concedidas, requirieron ser aceptadas y "validadas" por los interesados y, en su caso, afectados. Al mismo tiempo, el contrato muestra, en un caso concreto, el

${ }^{47}$ AGNEP, notaría 5, notario Patricio Carrasco, libro del primer semestre de 1891, 18 de abril, ff. 185-185v.

${ }^{48}$ AGNEP, notaría 5, notario Patricio Carrasco, libro del primer semestre de 1891, 18 de abril, f. 186v. 
interés del gobierno federal de beneficiar a los grandes industriales con concesiones de agua que tendrían como fin el establecimiento de grandes fábricas. Esto hace comprensible la posición tan ventajosa que tuvo Díaz Rubín ante Letona y Rueda. La fundación de La Covadonga no tuvo únicamente como protagonista a Díaz Rubín y su lucha por el control del agua, sino al gobierno federal y su política de concentrar en sí el control de los recursos hídricos.

De acuerdo con las concesiones federales, la construcción de la fábrica debía estar lista para 1897. José Díaz Rubín se ajustó a los tiempos. Además de la construcción del inmueble y la compra de maquinaria alemana, señaladamente 500 telares, en el lustro que corre entre 1891 y 1896, el industrial se avocó a construir los sistemas de aprovechamiento de agua y de dotar de comunicación al futuro centro fabril. En 1895, firmó un contrato con los propietarios del Ferrocarril Industrial de Puebla, que permitió la extensión del ramal que iba de Puebla a La Constancia hasta La Covadonga, e hizo el tendido de vías dentro de la propia fábrica para el traslado de la mercancía terminada. ${ }^{49}$

El sistema hidráulico de La Covadonga fue el punto final para el establecimiento de la fábrica. El 29 de marzo de 1897, Díaz Rubín consiguió otra concesión de la Presidencia de la República, en que se le permitía aprovechar como fuerza motriz 10,630 litros por segundo del río Atoyac, "por medio de una toma sobre la margen izquierda de ese río, debajo de su confluencia con la barranca de pilares, en los límites de los estados de Puebla y Tlaxcala", para el establecimiento de "una fábrica de hilados y tejidos de algodón". ${ }^{50}$

Con tal concesión pudo finalizar la construcción de las obras para el aprovechamiento del Atoyac. Díaz Rubín recorrió la presa de San Guillermo, en el extremo norte de su propiedad, unos metros río abajo. Ahí construyó el canal que derivó el agua hasta las turbinas de la fábrica, llevándola bajo el cárcamo de la fábrica por medio de túneles. Río abajo aprovechó la pequeña barranca del Sacro Monte para construir la presa de Moratilla, que sirvió como reserva

${ }^{49}$ AGNeP, notaría 5, notario Patricio Carrasco, libro II de 1895, 5 de noviembre, $f$. $176 \mathrm{v}$.

${ }^{50}$ AGNeP, notaría 5, notario Patricio Carrasco, 21 de enero de 1907, f. 44. 
de agua, y por medio del canal de desagüe devolvía el agua justo antes de la presa de la Beneficencia, que marcaba el límite sur de su propiedad. Con el canal, además, abastecía de agua potable el rancho, las casas de los trabajadores y la tienda, además del edificio central. Una vez concluida la construcción del sistema hidráulico, Díaz Rubín inauguró la fábrica, el 15 de octubre de 1897. Con este sistema se puso a la vanguardia de las fábricas textiles, pues basó la producción de La Covadonga en energía hidroeléctrica, en un punto que, además, recibía la mayor cantidad de agua del corredor, gracias a su ubicación privilegiada al extremo norte del Atoyac.

\section{Conclusiones}

El estudio del establecimiento de La Covadonga muestra cómo la aplicación de la ley del 5 de junio de 1888 en el corredor industrial del Atoyac requirió el acuerdo y la negociación de los propietarios de las fábricas establecidas en sus riberas, acostumbrados a considerar el agua como bien privado. En ese sentido, la conclusión central de mi contribución es que, si bien, la legislación de 1888 fue importante para el establecimiento de La Covadonga, al otorgar concesiones federales para el uso de las aguas del Atoyac, no por ello eliminó las antiguas prácticas de negociación entre los usufructuarios del río. De hecho, para conseguir aprovechar las concesiones federales otorgadas en la década de 1890, al amparo de la legislación de 1888, los usufructuarios del río debieron firmar acuerdos privados protocolizados ante notarios con los demás usuarios de la corriente fluvial, en una persistencia de prácticas entre particulares que habían caracterizado el reparto del recurso hídrico desde la instalación de las primeras fábricas textiles en el corredor industrial del Atoyac.

Asimismo, cabe destacar otros elementos a partir de lo expuesto. $\mathrm{Al}$ analizar el corredor industrial del Atoyac desde la perspectiva del agua, pues es notorio que fue la disponibilidad del recurso hídrico lo que permitió al valle de Puebla-Tlaxcala impulsar la industrialización textil entre 1835 y 1897, y garantizar su éxito hasta, por lo menos, 1911. Al perseverar en su estudio nos encontraremos con la muestra de que los industriales de la zona asumieron al agua como 
un bien privado que al ser usado por varios interesados fue fuente de negociaciones, acuerdos y conflictos. También veremos cómo el valor del agua aumentó conforme crecía la producción textil. Esto permitirá tener una perspectiva regional del porqué se interesó el gobierno federal en el control del recurso hídrico en 1888, combinando la mirada local con la nacional.

El caso estudiado muestra justamente el tránsito hacia un nuevo orden en lo que toca al control del agua. Al ser el objetivo de José Díaz Rubín controlar una parte del Atoyac para fundar La Covadonga, lo primero que hizo fue comprar diversos terrenos colindantes entre sí con una ubicación privilegiada, pues se localizaban entre el río y el principal camino interestatal. Una vez adquiridos logró reunir gran porción de terreno, que dominó un buen trecho del Atoyac, en el límite entre Puebla y Tlaxcala, con lo que obligó a los poseedores de fábricas en Puebla, río abajo, a negociar el tránsito y uso del agua. Por su parte, para conseguir el aprovechamiento absoluto del agua que entrara a su finca, obligó a los poseedores de fábricas en Tlaxcala, río arriba, a negociar con él gracias a que fue capaz de conseguir concesiones federales bajo el amparo de la ley de 1888 .

Una vez conseguido el control del recurso hídrico, procedió a construir su sistema de manejo del agua, que garantizó la implementación de un complejo de energía hidroeléctrica para potencializar la producción textil. Cuando se fundó La Covadonga, en 1897, Díaz Rubín había garantizado buen margen de éxito a su fábrica gracias al control que obtuvo, a partir de 1889, del agua. Éste lo consiguió, insisto, merced a la utilización de dos fuentes de dominio: el acuerdo tradicional y el novedoso Estado nacional. Conjugados, hicieron irrebatible a Díaz Rubín el dominio pleno del Atoyac a partir del 15 de octubre de 1897.

\section{SigLAS}

AHA, Archivo Histórico del Agua, México. AHAP, Archivo Histórico del Ayuntamiento de Puebla, Puebla. Agnep, Archivo General de Notarías de Puebla, Puebla. 
Hemerografía

El Pais, México, 1912.

BiBLIOGRAFÍA

Авогтеs, Luis, El agua de la nación. Una historia politica de México (1888-1946), México, Ciesas, 1997.

, "Del agua nacional al agua mercantil ambiental. Algunas ideas para hacer una investigación sobre historia contemporánea de los usos del agua en México", en Juan Manuel Durán, Martín Sánchez y Antonio Escobar, eds., El agua en la historia de México, México, cucsyн, Universidad de Guadalajara, El Colegio de Michoacán, 2005, 25-31.

Aguirre Anaya, Carmen, Personificaciones del capital. Siete propiedades en la sociedad e industria textil de Puebla durante el siglo XIX, Puebla, Universidad Autónoma de Puebla, 1987.

Bazant, Jan, "Evolution of the Textile Industry of Puebla 15441845", en Comparative Studies in Society and History, vol. 7, núm. 1, Cambridge University Press, octubre de 1964a, 56-69.

"Industria algodonera poblana de 1800-1843 en números", en Historia Mexicana, vol. 14, núm. 1, México, El Colegio de México, julio-septiembre de 1964b, 131-143.

Birrichaga Gardida, Diana, "La empresa de Cañerías de Puebla, 1855-1882", en Boletín del Archivo Histórico del Agua, 24, Conagua, Ciesas, AHA, 2003, 13-20.

, "Introducción", en Diana Birrichaga Gardida, comp., Agua e industria en México: Documentos sobre impacto ambiental y contaminación (1900-1936), Zinacantepec, El Colegio Mexiquense, Ciesas, 2008, 13-46.

Carabarín Gracia, Alberto, Agua y confort en la vida de la antigua Puebla, Benemérita Universidad Autónoma de Puebla, Insttit, Sociedad Mexicana de Historia de la Ciencia y de la Tecnología, México, 2000.

Castañeda González, Rocío, Las aguas de Atlixco. Estado, haciendas, fábricas y pueblos 1880-1920, México, Ciesas, AHA, El Colegio de México, 2005. 
Castellanos Arenas, Mariano, Tan lejos y tan cerca: los asaltos de fuerzas revolucionarias a la fábrica textil de Metepec (1911-1923), Puebla, Benemérita Universidad Autónoma de Puebla, Dirección de Fomento Editorial, 2009a.

Castellanos Arenas, Mariano, "El agua, la energía y la producción textil en la fábrica de Metepec, Atlixco, Puebla. 18981908”, en Rosalva Loreto López, coord., Agua, poder urbano y metabolismo social, Puebla, Benemérita Universidad Autónoma de Puebla, Instituto de Ciencias Sociales y Humanidades, 2009b, 167-216.

Contreras Cruz, Carlos, "La estructura productiva de la ciudad de Puebla y sus alrededores a finales del porfiriato", en Mario Cerutti, coord., De los borbones a la revolución. Ocho estudios regionales, México, GV Editores, Universidad Autónoma de Nuevo León, 1986, 159-180.

Escobar OHMstede, Antonio, "Introducción. La "modernización” de México a través del liberalismo. Los pueblos de indios durante el Juarismo", en Antonio Escobar Ohmstede, coord., Los pueblos de indios en tiempos de Benito Juárez, México, Universidad Autónoma de México, Universidad Autónoma Benito Juárez de Oaxaca, 2007, 11-35.

Estadistica de la república mexicana, 1880 (1880), México, Imprenta de Ignacio Cumplido.

Estrada Urroz, Rosalina, "Nuevas máquinas, menos hombres. La modernización de una empresa textil en Puebla: 'La Covadonga", en Leticia Gamboa y Rosalina Estrada, Empresas y empresarios textiles de Puebla. Análisis de dos casos, Cuadernos de Historia Contemporánea 1, Puebla, Universidad Autónoma de Puebla, Instituto de Ciencias, Centro de Investigaciones Históricas del Movimiento Obrero, Seminario de Historia Contemporánea, 1986.

Estrada Urroz, Rosalina, Del telar a la cadena de montaje. La condición obrera en Puebla, 1940-1976, Puebla, Benemérita Universidad Autónoma de Puebla, 1997.

FitTing, Elizabeth, “'Más sangre que agua’. Reclamos al Estado en el valle de Tehuacán”, en Francisco Javier Gómez Carpinteiro, 
ed., Paisajes mexicanos de la reforma agraria. Homenaje a William Roseberry, Zamora, El Colegio de Michoacán, Benemérita Universidad Autónoma de Puebla, Instituto de Ciencias Sociales y Humanidades Alfonso Vélez Pliego, Consejo Nacional de Ciencia y Tecnología, 2007, 37-70.

GAMBOA OJEDA, Leticia, Los empresarios de ayer. El grupo dominante en la industria textil de Puebla, 1906-1929, Puebla, Universidad Autónoma de Puebla, 1985.

, La urdimbre y la trama. Historia social de los obreros textiles de Atlixco, Puebla, Benemérita Universidad Autónoma de Puebla, Fondo de Cultura Económica, 2001. Molino de Enmedio. Una joya del patrimonio industrial poblano (1539-2000), Biblioteca Poblana de Historia y Cultura 4, Puebla, Instituto de Ciencias Sociales y Humanidades, Benemérita Universidad Autónoma de Puebla, Ayuntamiento de Puebla, 2005.

GAMBOA, Leticia y Rosalina EstradA, Empresas y empresarios textiles de Puebla. Análisis de dos casos, Puebla, Universidad Autónoma de Puebla, 1986.

Gamboa, Leticia y Blanca Estela Santibañez, "Tropiezos y logros de la metalurgia en el siglo xIx. La fundición de Panzacola, Tlaxcala", en Tzintzun, Revista de Estudios Históricos, núm. 19, Universidad Michoacana de San Nicolás de Hidalgo, Instituto de Investigaciones Históricas, enero-junio de 1994, 5-28.

García Cubas, Antonio, Cuadro geográfico, descriptivo e histórico de los Estados Unidos Mexicanos, México, Oficina Tipográfica de la Secretaría de Fomento, 1888.

Gómez Álvarez, Cristina, Puebla: los obreros textiles en la revolución, 1911-1918, Cuadernos de la Casa Presno 8, Puebla, Universidad Autónoma de Puebla, 1989.

Gómez Carpinteiro, Francisco Javier, "Comunidades de agua en el Nexapa. Liberalismo y centralización en el control local de recursos hidráulicos", en Francisco Javier Gómez Carpinteiro, ed., Paisajes mexicanos de la reforma agraria. Homenaje a William Roseberry, Zamora, El Colegio de Michoacán, Benemérita Universidad Autónoma de Puebla, Instituto de Ciencias Sociales y 
Humanidades Alfonso Vélez Pliego, Consejo Nacional de Ciencia y Tecnología, 2007, 133-165.

Gómez-GaLVARRIaTo, Aurora, "Fragilidad institucional y subdesarrollo: la industria textil mexicana en el siglo xIx", en Aurora Gómez-Galvarriato, coord., La industria textil en México, Lecturas de Historia Económica Mexicana, México, Instituto Mora, El Colegio de Michoacán, El Colegio de México, Instituto de Investigaciones Históricas, UNAM, 1999, 142-182.

Grosso, Juan Carlos, Estructura productiva y fuerza de trabajo. Puebla, 1830-1890, Cuadernos de la Casa Presno 1, Puebla, Universidad Autónoma de Puebla, 1984.

GutiérRez ÁlLVAREZ, Coralia, Experiencias contrastadas. Industrialización y conflictos en los textiles del centro-oriente de México, 18841917, México, El Colegio de México, Instituto de Ciencias Sociales y Humanidades, Benemérita Universidad Autónoma de Puebla, 2000.

Keremitsis, Dawn, La industria textil mexicana en el siglo XIX, SepSetentas 67, México, Secretaría de Educación Pública, 1973. Lafrance, David G., "Los obreros y la Revolución mexicana: El Presidente Francisco I. Madero y los trabajadores Textiles de Puebla", en Boletín de Investigación del Movimiento Obrero, 6, Centro de Investigaciones Históricas del Movimiento Obrero, Instituto de Ciencias, Universidad Autónoma de Puebla, 1983, 6-48.

Loreto López, Rosalva, "De aguas dulces y aguas amargas o de cómo se distribuía el agua en la ciudad de Puebla durante los siglos XVIII y xIx" en Rosalva Loreto López y Francisco Javier Cervantes Bello, coords., Limpiar y obedecer, la basura, el agua y la muerte en la Puebla de los Angeles 1650-1925, México, Universidad Autónoma de Puebla, Colegio de Puebla, Centro de Estudios Mexicanos y Centroamericanos, 1994.

, Los conventos femeninos y el mundo urbano de la Puebla de los Ángeles del siglo XVIII, México, El Colegio de México, 2000. , Una vista de ojos a una ciudad novohispana. La Puebla de los Ángeles del siglo XVIII, Puebla, Benemérita Universidad Autónoma de Puebla, Instituto de Ciencias Sociales y Humanidades, Consejo Nacional de Ciencia y Tecnología, 2008. 
LORETo López, Rosalva, coord., Agua, poder urbano y metabolismo social, Estudios Urbanos y Ambientales 1, Puebla, Benemérita Universidad Autónoma de Puebla, Instituto de Ciencias Sociales y Humanidades, 2009.

Mendoza García, Edgar, "Galerías filtrantes: la disputa por el agua del subsuelo en el valle de Tehuacán, 1900-1930", en Juan Manuel Durán, Martín Sánchez y Antonio Escobar, eds., El agua en la historia de México, México, Centro Universitario de Ciencias Sociales y Humanidades de la Universidad de Guadalajara, El Colegio de Michoacán, 2005, 221-236.

Puebla en el centenario, edición especial de "La Ilustración", México, Imprenta Lacaud, 1910.

Pallares, Eduardo, Colección de códigos y leyes federales. Tierras, bosques, aguas, ejidos, colonización y el gran registro de la propiedad. Novisima edición ordenada y anotada con arreglo a las últimas disposiciones vigentes, por el Licenciado... Contiene todas las circulares de la Comisión Nacional Agraria, algunas de las cuales no han sido publicadas oficialmente, México, Herrero Hermanos Sucesores, sf.

Rivero Quijano, Jesús, La revolución industrial y la industria textil en México, 2 tomos, México, Joaquín Porrúa editores, Cámara Nacional de la Industria Textil, 1990.

RosARIO JimÉnez, Sandra, "El uso y la distribución del agua durante el reparto agrario en Acatzingo, Puebla, 1915-1936", tesis de licenciatura en historia, Puebla, Benemérita Universidad Autónoma de Puebla, 2008.

Salazar Exaire, Celia, Uso y distribución del agua en el valle de Tehuacán. El caso de San Juan Bautista Axalpan, Puebla (16101798), Colección Científica 402, México, Instituto Nacional de Antropología e Historia, 2000.

,"El agua en la conformación de la ciudad de Puebla", en Boletin del Archivo Histórico del Agua, 32, México, Conagua, Ciesas, AHA, 2006, 39-49.

Salazar Exaire, Celia, Margarita Peña Loredo, Enrique Gómez Osorio y Jesús Joel Peña Espinosa, Entre la fe y la guerra. Memoria e identidad en torno al fuerte de Loreto, Puebla, INAH, Universidad de las Américas, Secretaría de Cultura de Puebla, 2007. 
SÁnchez Guillermo, Evelyne, "El agua como espacio de conflicto en la primera industrialización de México", en ConCiencia política, 2: 3, El Colegio de Veracruz, 2003, 191-212.

"La industrialización de Puebla y el control del agua a mediados del siglo xIx. Conflictos y redes de los nuevos empresarios”, en María de Lourdes Herrera Feria, coord. „Estampas de la vida angelopolitana. Ensayos de historia social del siglo XVI al XX, Tlaxcala, El Colegio de Tlaxcala, Benemérita Universidad Autónoma de Puebla, 2008, 103-119.

SÁnchez Rodríguez, Martín, “El mejor de los títulos”. Riego, organización social y administración de recursos hidráulicos en el Bajio mexicano, Zamora, El Colegio de Michoacán, Gobierno del Estado de Guanajuato, Comisión Estatal del Agua, 2005.

SuÁrez Cortez, Blanca Estela, "Industria y agua en el centro de México (1835-1850)”, en Blanca Estela Suárez Cortez y Diana Birrichaga Gardida, coords., Dos estudios sobre usos del agua en México (siglos XIX y XX), México, Ciesas, IMTA, 1997, 11-90.

, "Poder oligárquico y usos del agua: Querétaro en el siglo XIX (1838-1880)", en Blanca Estela Suárez Cortez, coord., Historia de los usos del agua en México: oligarquias, empresas y ayuntamientos, 1840-1940, México, Conagua, Ciesas, IMTA, 1998, 15-104.

Thomson, Guy P. C., "Continuidad y cambio en la industria manufacturera mexicana, 1800-1870”, en Aurora Gómez-Galvarriato, coord., La industria textil en México, Lecturas de Historia Económica Mexicana, México, Instituto Mora, El Colegio de Michoacán, El Colegio de México, Instituto de Investigaciones Históricas, unAM, 1999, 53-113.

, Puebla de los Ángeles. Industria y sociedad de una ciudad mexicana, 1700-1850, Puebla, Benemérita Universidad Autónoma de Puebla, Universidad Iberoamericana, Instituto Mora, 2002.

Torres Bautista, Mariano Enrique, La familia Maurer de Atlixco, Puebla. Entre el Porfiriato y la Revolución, Conaculta, México, 1994.

El origen de la industrialización de Puebla, Claves Latinoamericanas, México, El Colegio de Puebla, 1995. 
Valladares de la Cruz, Laura R., Cuando el agua se esfumó. Cambios y continuidades en los usos sociales del agua en Morelos, 1880 1940, México, Universidad Nacional Autónoma de México, Facultad de Estudios Superiores Cuautitlán, 2003.

Ventura Rodríguez, María Teresa, "La tecnología de la temprana industria textil en Puebla durante el siglo XIx", en María Teresa Ventura Rodríguez, coord., Aproximaciones al estudio de la infraestructura en Puebla a través de su historia gremial e industrial, Puebla, Instituto de Ciencias Sociales y Humanidades, Benemérita Universidad Autónoma de Puebla, 2009, 35-49.

, Una mirada al sindicalismo de ayer a través de La Constancia

Mexicana, Puebla, Benemérita Universidad Autónoma de Puebla, Instituto de Ciencias Sociales y Humanidades, 2011.

Fecha de Recepción del artículo: 22 de julio de 2011

FECHA DE RECEPCIÓN DE LA VERSIÓN FINAL: 17 de julio de 2012 